\title{
CONDROMA MANDIBULAR ASSOCIADO A CISTO MEDIANO DE MANDÍBULA (com epitélio do tipo respiratório) APRESENTAÇÃO DE UM CASO
}

\author{
João Jorge Barbachan * \\ Pantelis Varvaki Rados* \\ Manoel Sant'A na Filho* \\ Onofre Quadros* \\ Icleo Faria Souza **
}

BARBACHAN, João Jorge et alii. Condroma mandibular associado a cisto mediano de mandíbula (com epitélio do tipo respiratório) - Apresentação de um caso. Revista da Faculdade de Odontologia, Porto Alegre, 25:67-75, 1983.

Descritores: Tumores bucais - Condroma - Mandíbula, cistos - Cistos não odontogênicos

\section{RESUMO}

É apresentado um caso de condroma intra-ósseo localizado na região anterior da mandíbula e que estava associado a um cisto mediano, em uma mulher de 41 anos, da raça brança.

\section{REVISÃO DA LITERATURA}

O condroma é uma lesão intra-oral rara $(13,17,28)$ com localização preferencial pela maxila $(13,18)$. Na mandíbula existem alguns casos publicados em que o tumor estava relacionado com o côndilo e o processó coronóide, e que à medida que o tumor se desenvolvia causava assimetria da face e disfunção mas- tigatória progressiva $(3,6,15,20,24)$. Existem alguns casos de condroma de língua $(9,10,14,16,28)$, palato (25), processo zigomático (1) e também na sínfise mandibular $(3,8)$. Para Gorlin (13) estas lesões devem ser encaradas com muita cautela por não serem raras as suas transformações malignas. Lucas (18) coloca, que antes de se basear no aspecto histológico destas lesões, para se estabelecer a terapêutica adequada, deve-se levar em conta a localização e o acesso para a sua remoção, pois a sua transformação maligna não está bem esclarecida.

O aspecto radiográfico do condroma é variável, desde uma área radiolú-

\footnotetext{
* Professores de Patologia Buco-Dental das Faculdades de Odontologia da UFRGS e PUCRGS * * Professor de Radiologia das Faculdades de Odontologia da UFRGS e PUCRGS
} 
cida até com radiopacidade no seu interior $(13,18)$.

O condroma para Allan e Scott (3) seria um distúrbio de desenvolvimento antes de um tumor propriamente dito, idéia esta não aceita pela maioria $(1,10$, $13,18,25)$.

O aparecimento de células formadoras de cartilagem, seria, explicado pela permanência de remanescentes da cartilagem de Meckel $(4,14)$, por aparecimento de cartilagem secundária na mandíbula (18), por presença de condroblastos nas inserções dos tendões ou mesmo porque a mandíbula apresenta zonas de crescimento mais acelerado em algumas áreas $(6,18)$.

O cisto mediano mandibular, é uma lesão controvertida quanto a sua origem, para alguns autores $(12,17,23,26)$ seria um distúrbio de desenvolvimento, e para outros apenas a presença de um cisto primordial nesta, área da mandíbula $(4,7,12,17,21,23,26)$, um cisto periodontal lateral (23) ou como White et alii (27) colocaram em seu trabalho, inclusões epiteliais durante o período final da fusão da mandíbula ou também por inclusão de glândulas salivares na mandíbula. $O$ tratamento de escolha para estas lesões é a curetagem $(2,4,5,7$, $12,17,22,23,26,27)$ mesmo em lesões extensas como a apresentada por Salman e Harrigan (22). O aspecto radiológico é geralmente unilocular $(2,7$, 26) podendo apresentar-se multiloculado $(19,22)$. O epitélio que reveste o cisto tem aspectos variáveis desde epitélio estratificado pavimentoso $(12,17,20$, $22,23,26,27)$ até epitélio do tipo ciliado $(12,17,23,26,27)$, fato este que causa alguma surpresa, e que segundo Gorlin (11) e Albens (2) seria explicado pela potencialidade que as células epite- liais tem de se transformarem. Arwill e Kahnberg (4) apresentaram um caso de condroma associado a um cisto primordial, na mandíbula de um paciente de 59 anos.

\section{APRESENTAÇÃO DO CASO}

Paciente de 41 anos do sexo feminino, casada, que durante levantamento radiográfico de rotina para tratamento periodontal, na clínica do Dr. Hugo Gigante, mostrou uma área radiolúcida multilocular na mandíbula, região correspondente aos ápices dos incisivos central e lateral do lado direito, e medindo aproximadamente $0,5 \mathrm{~cm}$ de diâmetro. Os dentes se apresentavam hígidos e não estavam em relação com a lesão (figura 1). O material enviado pelo Dr. Lauro Rosa e recebido no laboratório de $\mathrm{Pa}$. tologia Buco-Dental da PUCRGS apresentava:

Aspecto Macroscópico: Um fragmento de tecido mole, de forma arredondada, consistência fibrosa, cor parda e pesando $200 \mathrm{mg}$, fixado em formol $10 \%$, seguiu o método de rotina para inclusão em parafina, os cortes tinham 5 micra de espessura e foram coloridos pela Hematoxilina/Eosina.

Aspecto Microscópico: Formação excessiva de cartilagem hialina com septos de tecido conjuntivo fibroso. As células de cartilagem se apresentavam com formas e tamanhos variáveis algumas com dois núcleos e o citoplasma fracamente eosinófilo. Os parâmetros histológicos para o diagnóstico de condroma e condrosarcoma são muito subjetivos, nós optamos pelo diagnóstico histopatológico de condroma (figura 2). 
Nota-se ainda uma cavidade cística revestida por epitélio pseudo-estratificado ciliado (figura 3). Diagnóstico Histopatológico: Condroma Associado a Cisto Mediano da Mandíbula. O controle radiográfico da paciente 5 meses após mostrou a reparação óssea na área da lesão (figura 4).

\section{DISCUSSÃO}

Concordamos com $(13,18,25)$ quando dizem que o condroma é um tumor raro quando em localização intrabucal. Quanto ao aparecimento de condroblastos na mandíbula existem várias teorias $(4,14,18)$, além do fato de que, todas as células mesenquimais indiferenciadas guardam a potencialidade de se diferenciarem em condroblastos $(6,9)$ uma vez que têm origem no mesmo foIheto embrionário. A presença do Cisto Mediano da Mandíbula é algo raro (23), e o fato de o epitélio do Cisto ser do tipo respiratório é mais raro ainda (12, $17,23,26,27)$, a sua presença é mais uma vez explicada pela potencialidade que as células epiteliais da mucosa bucal tem de se diferenciarem umas nas outras $(11,17)$ já que num dado momento embrionário elas partem de um mesmo tecido. Concordamos com Arwill e Kahnberg (4) quando dizem que a concomitância de um condroma com um cisto primordial, neste caso Cisto Mediano de Mandíbula, seria uma casualidade.

\section{SUMMARY}

The authors present a case of a Chondroma related with the anterior mandible that is associated with a median mandibular cyst in a woman 41 years old. 


\section{REFERÊNCIAS BIBLIOGRÁFICAS}

1. AGUIAR, S.A. \& CARVALHO, P.P. - Osteocondroma do processo zigomático (relato de um caso). Rev. Assoc. Paul. Cirurg. Dent., 33(6):490-4, 1979.

2. ALBERS, D.D. - Median mandibular cyst partially lined with pseudostratified columnar epitheliun: report of a case. Oral Surg., 36(7):11-5, 1973.

3. ALLAN, J.H. \& SCOTT, J. - Osteochondroma of the mandible, report of two cases. Oral Surg., 37(4):556-65, 1974.

4. ARWILL, T. \& KAHNBERG, K.E. - Odontogenic keratocyst associated with an intramandibular chondroma. J. Oral Surg., 35(1):64-7, 1977.

5. BEATTY, R.E. - Case report: median mandibular cyst. Dent. Surv., 48(11): 27-8, 1972.

6. BRADY, F.A. et alii. Extracondilar osteochondroma of the jaws. Oral Surg., $46(5): 658-78,1978$.

7. BUCHNER, A. \& RAMON, Y. - Median mandibular cyst. - A rare lesion of debatable origin. Oral Surg., 37(1):431-7, 1974.

8. DAWIS, G. \& TIDEMAN, H. - Chondromyxoide fibroma of the mandible, case report. Int. J. Oral Surg., 7(1):23-6, 1978.

9. DEL RIO, C.E. - Chondroma of the tongue. Review of the literature and a case report. J. Oral Med., 33(2):54-6, 1978.

10. GABRIELE, R. \& KAUFMAN, P.S. - Osteochondroma of the tongue, report of a case. J. Oral Surg., 36(6):476-7, 1978.

11. GORLIN, R.J. - Potentialities of the oral epitheliun manifest by mandibular dentigerous cyst. Oral Surg., 10(3):271-84, 1957.

12. _ - Median mandibular cyst. In: GORLIN, R.J. \& GOLDMAN, H.M. Thoma's oral pathology. 6.ed. St. Louis, Mosby, 1970. p.462-3.

13. - Chondroma. In: GORLIN, R.J. \& GOLDMAN, H.M. Thoma's oral pathology. 6.ed. St. Louis, Mosby, 1970. p.566.

14. GUTMAN, J. et alii - Chondroma of the tongue - repor of a case. Oral Surg., 37(1):75-7, 1974.

15. JAMES, R.B. et alii - Osteochondroma of the mandibular coronoid process. Report of a case. Oral Surg., 37(2):189-95, 1974.

16. JUNQUEIRA, H.R. et alii - Condroma de língua. Arq. Cent. Est. Cur. Odont. UFMG., 19(1):93-100, 1982.

17. LUCAS, R.B. - Median mandibular cyst. In: LUCAS, R.B. - Pathology of tumours of the oral tissues. 3.ed. London, Churchil Livingstone Ed., 1976. p. 355-6.

18. - Chondroma. In: LUCAS, R.B. - Pathology of tumours of the oral tissues. 3.ed. London, Churchil Livingstone Ed., 1976. p. 181-91.

19. LUCCHESI, F.J. \& TOPAZIAN, D.S. - Multilocular median developmental cyst of the mandible. Repor of a case. J. Oral Surg., 19(7):336-8, 1961.

20. RAMON, Y. et alii. - Osteochondroma of the coronoid process of the mandible. Oral Surg., 43(5):692-7, 1977. 
21. ROBINSON, H.B.G. - Cyst of the oral cavity. In: ARCHER, W.H. - Manual of oral surgery. 3.ed. Philadelphia, Saunders, 1952. p.227.

22. SALMAN, L. \& HARRIGAN, W.F. - Decompression of median mandibular cyst. Report of a case. J. Oral Surg., 30(7):503-5, 1972.

23. SHAFFER, W.G. - Cisto mediano de mandíbula. In: - Patologia bucal. (A text book of oral pathology). 3.ed. Rio de Janeiro, Interamericana, 1979. p.60-1.

24. SIMON, G.T. et alii. - Osteochondroma of the mandibular condyle: case report and its management. Oral Surg., 43(1):18-24, 1977.

25. SNYDNER, S.R. \& MERKOW, L.P. - Benign chondroma of palate: report of a case. J. Oral Surg., 31(11):873-5, 1973.

26. TILSON, H.B. \& BAUERLE, J.E. - Median mandibular cyst: report of a case. J. Oral Surg., 28(7):519-20, 1970.

27. WHITE, D.K. et alii. - Median mandibular cyst: review of the literature and report of two cases. J. Oral Surg., 33(5):372-5, 1975.

28. ZEGARELLI, D.J. - Chondroma of the tongue. Oral Surg., 43(5):738-45, 1977. 


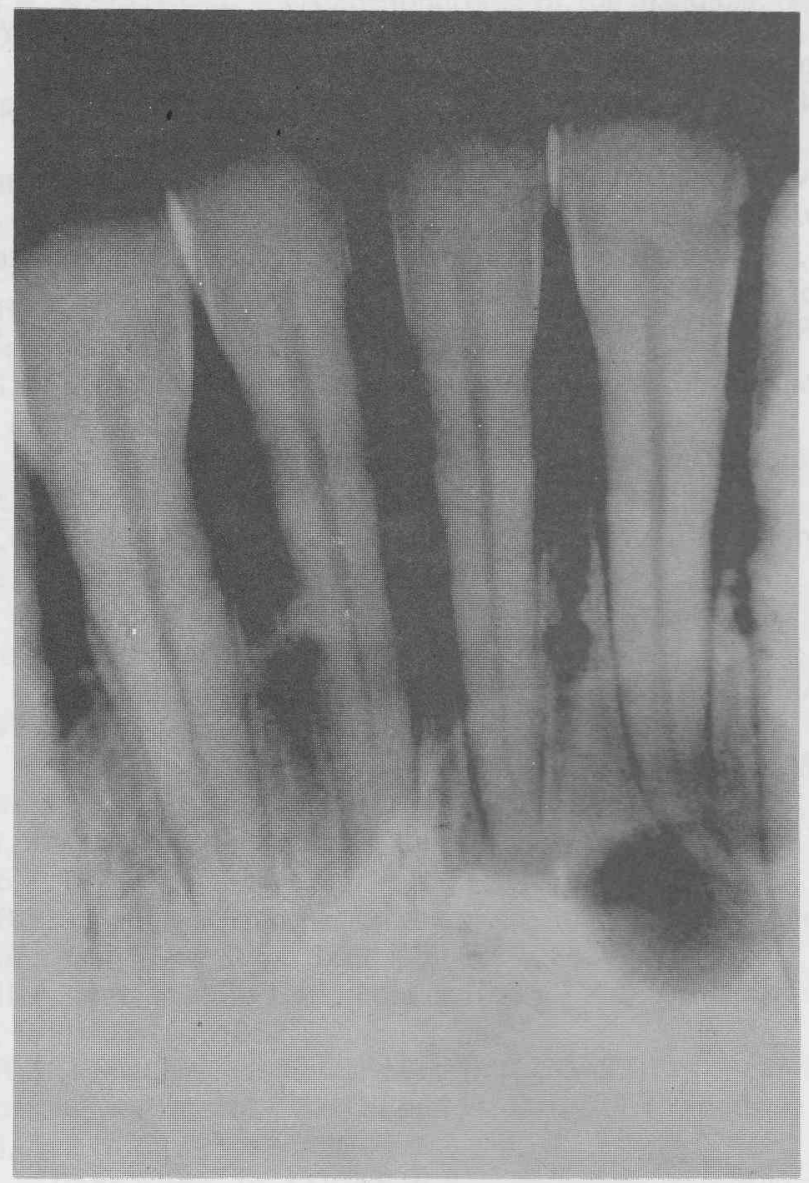

Fig. 1 - Dentes higidos e sem relação com a lesão. 


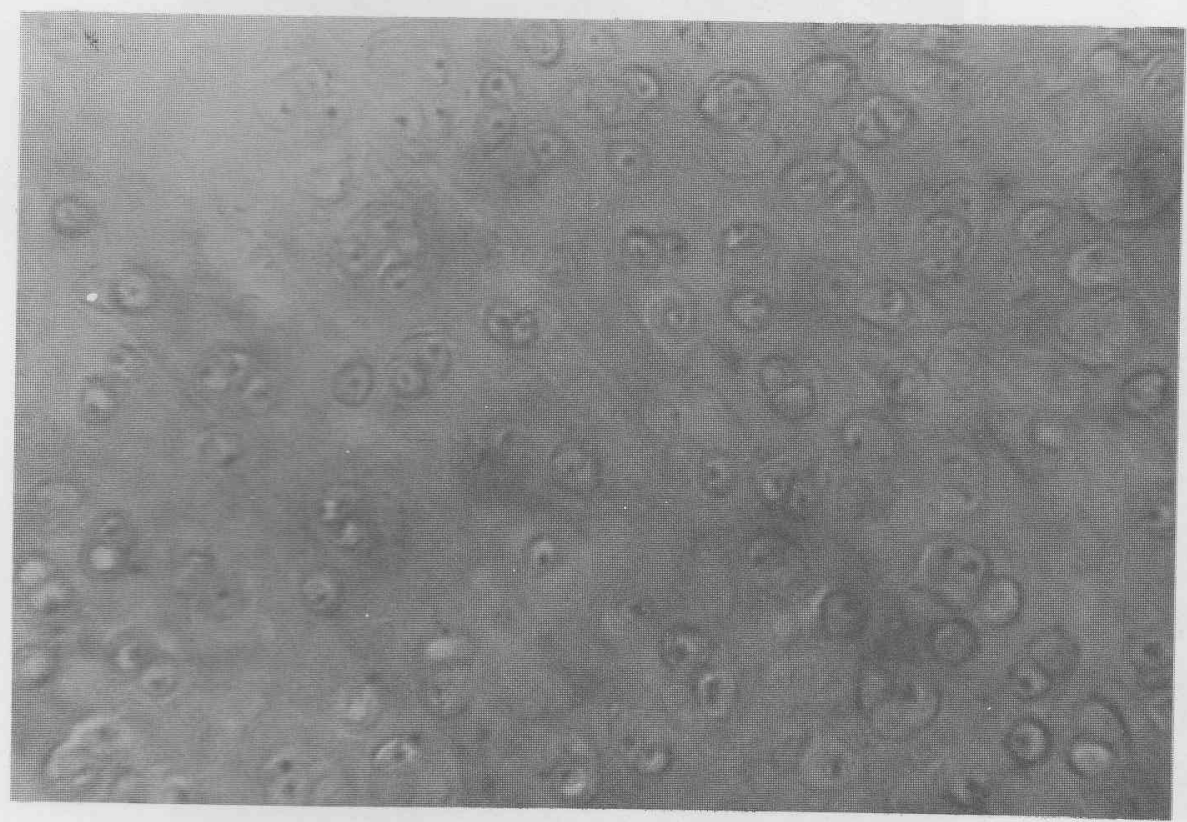

Fig. 2 - Aspecto histopatológico do condroma 


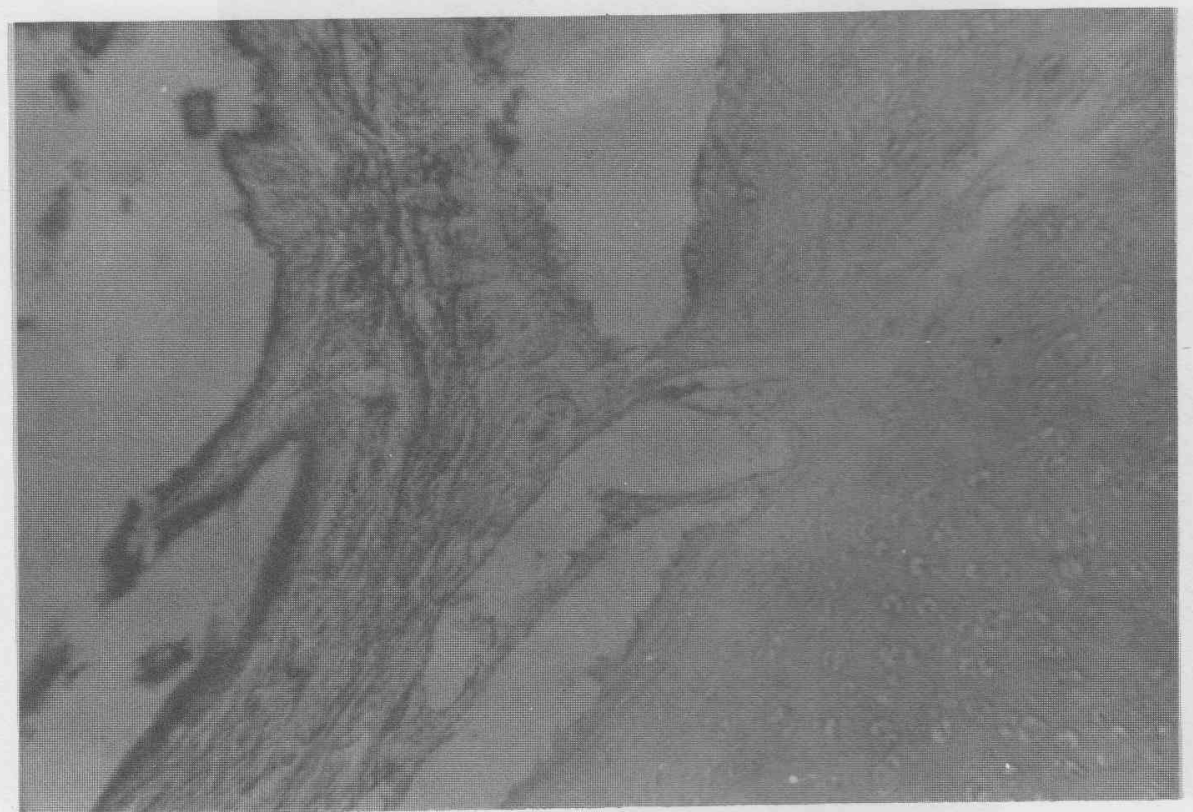

Fig. 3 - Aspecto histopatológico da cavidade cistica atapetada por epitélio ciliado.

R. Fac. Odont. P.A. 


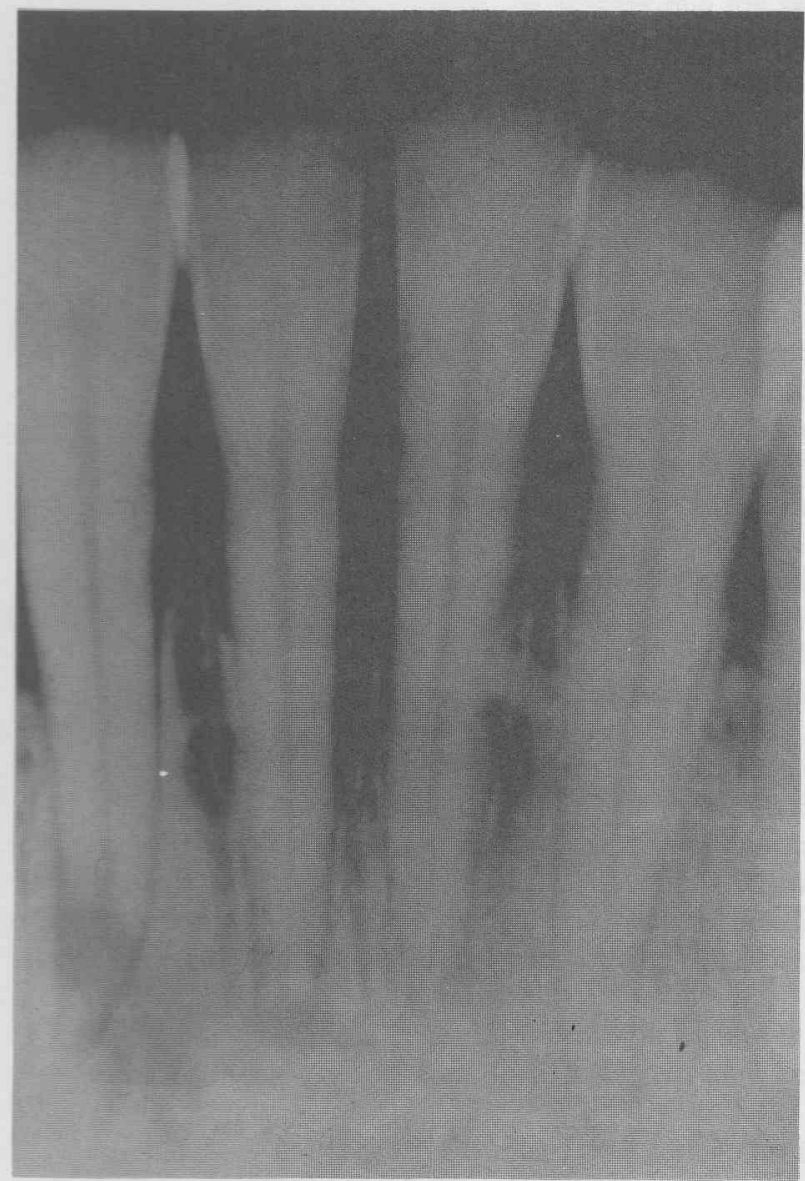

Fig. 4 - Aspecto radiográfico da reparação óssea após 5 meses 